\title{
Parathyroid Hormone Increases the Concentration of Insulin-like Growth Factor-I and Transforming Growth Factor Beta 1 in Rat Bone
}

Johannes Pfeilschifter, Frank Laukhuf, Bernd Müller-Beckmann, Werner F. Blum, Thomas Pfister, and Reinhard Ziegler University of Heidelberg, Department of Internal Medicine I, D-69115 Heidelberg; Boehringer Mannheim GmbH,

D-68305 Mannheim; and Lilly GmbH, Bad Homburg D-61350, Germany

\begin{abstract}
Intermittent treatment with parathyroid hormone (PTH) increases bone mass in experimental animals and humans. In vitro studies have suggested that the anabolic effect of PTH may be mediated by local growth factors. However, the relevance of these findings to in vivo situations remains unclear. In this study, we examined a time course of daily s.c. injections of hPTH(1-34) on the skeletal concentration of insulin-like growth factor (IGF)-I, IGF-II, and transforming growth factor $\beta$ (TGF- $\beta$ ) in the proximal tail vertebrae of male rats. PTH caused a time and dose-dependent increase in the bone mineral density of the lumbar spine. This anabolic effect on bone mass was accompanied by progressive increases in bone matrix-associated IGF-I and TGF- $\beta 1$. Increases in IGF-I and TGF- $\beta 1$ became apparent after four and eight weeks of PTH treatment respectively and persisted through week 12. PTH had no effect on circulating IGF-I, suggesting that the increase of bone matrix IGF-I was due to the local effect of PTH on bone tissue directly rather than to an increase of circulating IGF-I. These data are consistent with the hypothesis that IGF-I and TGF- $\beta 1$ may play a role as local mediators of the anabolic effects of PTH on bone metabolism. (J. Clin. Invest. 1995. 96:767-774.) Key words: bone mineral density • extracellular matrix - extraction - hydroxyproline - growth factors
\end{abstract}

\section{Introduction}

Due to the fact that it has been found to stimulate bone formation in laboratory animals (1-5), as well as in human beings (69 ), intermittent application of parathyroid hormone (PTH $)^{1}$ is

Part of this work was presented at the XXIII. Symposium of the European Society for Calcified Tissues, Heidelberg, April 1993 and at the 16th Annual Meeting of the American Society for Bone and Mineral Research, Kansas City, September 1994.

Address correspondence to Johannes Pfeilschifter, MD, University of Heidelberg, Department of Internal Medicine I, Bergheimer Straße 58, D-69115 Heidelberg, Germany. Phone: 6221-163473; FAX: 6221563101.

Received for publication 13 October 1994 and accepted in revised form 20 April 1995.

1. Abbreviations used in this paper: BMD, bone mineral density; IGFBP, insulin-like growth factor binding protein.

J. Clin. Invest.

(C) The American Society for Clinical Investigation, Inc.

0021-9738/95/08/0767/08 $\$ 2.00$

Volume 96, August 1995, 767-774 currently being investigated for its possible usage in the treatment of various skeletal diseases such as osteoporosis. Many data lead one to the assumption that the anabolic effects of PTH on bone formation occur via an increased synthesis of local growth factors in the bone tissue. Of the various potential anabolic growth factors that could be modulated by PTH, the insulin-like growth factors (IGF) and transforming growth factor beta (TGF- $\beta$ ) have received the most attention. These factors are found in bone matrix in great abundance and are known stimulators of bone cell replication and matrix synthesis (10). In osteoblast-enriched cultures of fetal rat bone cells (11), as well as in rat bone organ cultures (12), PTH has been shown to stimulate IGF-I production at the transcriptional and polypeptide levels. The role of IGF-I as mediator of the anabolic effects of PTH on bone formation is additionally supported by findings that the stimulation of collagen synthesis in cultured rat calvariae after transient PTH administration can be suppressed by antibodies to IGF-I (13). PTH has also been reported to stimulate the secretion of IGF-II in mouse calvariae cultures $(12,14)$, whereas Oursler et al. observed a dose-dependent stimulation of TGF- $\beta$-bioactivity and TGF- $\beta 1$-message with PTH in cultures of human osteoblast-like cells (15).

The relevance of these findings in vivo, however, is largely unknown. The biologically active tissue concentration of growth factors in vivo is not only determined by their local secretion but also by their interactions with extracellular matrix proteins and by adsorption of growth factors derived from the systemic circulation. The extracellular matrix appears to play a critical role in controlling the distribution of growth factors and in the presentation of growth factors to responding cells. Due to its abundant mineralized extracellular matrix, bone offers the opportunity to measure growth factors after they have been sequestered in vivo. To determine whether the intermittent administration of PTH increases anabolic growth factor sequestration into bone matrix and thereby may exert its anabolic effect on bone mass, we quantitatively extracted bone matrix from rat tail vertebrae after various intervals of PTH administration and then assayed the extracts for IGF-I, IGF-II, and TGF- $\beta$.

\section{Methods}

\section{Experimental design}

Male Wistar rats, $60 \mathrm{~d}$ old and weighing $\sim 160$ grams, were randomly allocated into 16 groups, each of which contained six rats. The animals were kept in pairs, had free access to water and were fed a standard diet, containing $1.2 \%$ calcium. Daily subcutaneous injections of either vehicle or hPTH(1-34) (GBF, Braunschweig, Germany) in doses of 4,10 , or $40 \mu \mathrm{g} / \mathrm{kg}$ body weight for $2,4,8$, or $12 \mathrm{wk}$ were administered every morning. $24 \mathrm{~h}$ after the final PTH-injection, blood was drawn for differential serum assays, and the animals were thereafter sacrificed.

Bone mineral measurements

Bone mineral density (BMD) of lumbar vertebrae L1-4 was determined after sacrifice by dual-energy $x$-ray absorptiometry using a HOLOGIC 
QDR-1000 instrument (Waltham, MA). The coefficient of variation of the measurements was $1.3 \%$.

\section{Bone matrix extraction}

After sacrifice, the proximal 5 tail vertebrae were dissected and freed of adherent soft tissue. Cartilagenous parts and the end plates of each vertebra were carefully removed. Due to the small size of the vertebrae, it was not feasible to completely separate cortical from trabecular bone. However, preceding measurements in rat bones comparing pooled samples of trabecular and cortical bone had revealed similar concentrations of IGF-I, IGF-II, and TGF- $\beta$ bioactivity in the two compartments. After cleaning, the vertebrae were immersed in liquid nitrogen and mechanically crushed into small fragments of several millimeters in diameter. The fragments were washed repeatedly in cold distilled water until the washings were free of blood and defatted in cold isopropylether. The defatted bone fragments were then ground into smaller particles (40-60 $\mu \mathrm{m}$ ) in a liquid nitrogen-cooled freezer mill (Raetsch, Haan, Germany). Fluorometrically measured DNA content in the extracts was below detection limit ( $50 \mathrm{ng} \mathrm{DNA} / 20 \mathrm{mg}$ bone powder), indicating minimal cellular contamination of the bone powder.

For each bone sample, four parallel extractions were performed. 20 mg of lyophylized bone powder were placed in microcentrifuge tubes ("Twist-Lock", Eppendorf, Hamburg, Germany) and $1.7 \mathrm{ml}$ of extraction solution ( see below) was added. Spectrapor 3 dialysis tubing (3.5kD cutoff; Spectrum Medical Industries, Houston, TX) was then placed over the tube opening and secured by a melted out tube cap, as described by Overall et al. (16). The tubes were then inverted and firmly fixed upside down in a circular rack floating on top of the extraction solution ( $600 \mathrm{ml}$ for 30 tubes). Extraction was achieved by dialysis against 0.05 M tetrasodium EDTA (Serva, Heidelberg, Germany), 4 M Guanidin$\mathrm{HCl}$ (Sigma, Deisenhofen, Germany), $30 \mathrm{mM}$ Tris (Merck, Darmstadt, Germany), and $1 \mathrm{mg} / \mathrm{ml}$ bovine serum albumine (Sigma; RIA grade) at a $\mathrm{pH}$ of 7.4. The following protease inhibitors were added to the extraction solution: $5 \mathrm{mM}$ benzamidine- $\mathrm{HCl}, 1 \mathrm{mM}$ phenylmethyl-sulfonyl fluorid, and 0.1 M $\epsilon$-aminocaproic acid (Sigma). Dialysis was carried out at $4^{\circ} \mathrm{C}$ under constant stirring for $24 \mathrm{~h}$. Preceding experiments had shown that demineralization was $100 \%$ complete by this time and that the yield of extractable growth factors could not be improved by reextraction (data not shown). No additional growth factors were released when the residual bone matrix was digested with highly purified collagenase as well (Calbiochem, Bad Soden, Germany). After extraction, the samples were redialysed against cold PBS ( $\mathrm{pH} \mathrm{7.4)} \mathrm{for} 72 \mathrm{~h}$. Dialysis medium ( $600 \mathrm{ml}$ for 30 tubes) was replaced every $24 \mathrm{~h}$. The supernatant extracts were recovered after centrifugation at $5,000 \mathrm{~g}$ for $10 \mathrm{~min}$ and stored at $-80^{\circ} \mathrm{C}$ until assayed for growth factor activity.

\section{Determination of extraction performance}

Recovery. To determine total recovery parameters, bone powder was spiked with known amounts of purified TGF- $\beta 1$ and IGF-I before extraction. The mean recovery of IGF-I and TGF- $\beta 1$ was 105 and $96 \%$, respectively.

Parallelism. To assess linearity of the extraction procedure 5, 10, or $20 \mathrm{mg}$ of three different preparations of bone powder containing high, medium, and low amounts of IGF-I were extracted and then assayed. The mean of the observed/expected results was $>95 \%$ for all samples.

Between assay variation. The combined inter-assay variance of the extraction and measurement procedure was determined by extracting three pools of bone matrix containing low, medium, and high concentrations of TGF- $\beta 1$, IGF-I, or IGF-II over a period of time $(n=12)$ and assaying the concentration of these growth factors individually by duplicate measurements for all immunoassays and fourfold measurements for TGF- $\beta$-bioactivity. Inter-assay variance was $9.8 \%$ for IGF-I, $14 \%$ for IGF-II, $12 \%$ for immunoreactive TGF- $\beta 1$, and $34 \%$ for TGF$\beta$ bioactivity.

\section{IGF-I measurements}

IGF-I in the tissue extracts was quantified by RIA, using a polyclonal rabbit antibody specific for human IGF-I (Mediagnost, Tübingen, Ger- many) and recombinant human IGF-I (GroPep, Adelaide, Australia) as a tracer and standard. For each bone sample, extracts from three separate extractions were assayed in duplicate and the means calculated as human IGF-I equivalent. Dilution curves of bone extracts and of rat serum showed good parallelism with the standard curves prepared with the human IGF-I. IGF-binding protein (IGFBP) artifacts were avoided by initial dissociation of IGF from the IGFBP's present using an acidic buffer. Reassociation was then blocked by inducing IGFBP saturation through the addition of excess IGF-II (Mediagnost) (17). Validation of the assay for bone matrix extractions was performed by showing 1 . complete recovery of added unlabeled human IGF-I after preincubation with the extracts, 2 . no change in the measurement of endogenous IGFI in the presence of up to $10 \mathrm{ng} / \mathrm{ml}$ IGFBP-3 which was the highest concentration of IGFBP-3 added. IGF-II cross-reactivity in this RIA was found to be less than $0.05 \%$ with an inter-assay variation of $5.6 \%$ and a sensitivity level of $0.1 \mathrm{ng} / \mathrm{ml}$. As with all samples, serum IGF-I was measured in duplicate using the same assay procedure.

\section{IGF-II measurements}

IGF-II was measured by RIA using an anti-IGF-II antibody obtained by immunization of rabbits using the synthetic peptide IGF-II (33-40) as described earlier (17). Cross-reactivity of the IGF-II antibody with IGF-I was $<0.05 \%$. All measurements were calibrated against recombinant human IGF-II (GroPep). Dilution curves of bone extracts and of rat serum were parallel to standard curves prepared with the human IGF-II. Assay conditions were similar to those described for the IGF-I RIA, except that excess IGF-I was used to block interferences caused by IGFBPs. Validation was performed as described for IGF-I. Interassay coefficients of variations were $5.4 \%$ at a sensitivity level of 0.1 $\mathrm{ng} / \mathrm{ml}$. Serum IGF-II was measured in duplicate using the same assay procedure.

\section{TGF- $\beta$ measurements}

Skeletal TGF- $\beta$ was determined by the mink lung cell bioassay (18, 19 ) and by specific enzyme-linked immunosorbend assays (ELISA) for TGF- $\beta 1$ and TGF- $\beta 2$. For total TGF- $\beta$ bioactivity quantification, mink lung cells (Mv1Lu, CCL64; American Type Culture Collection, Rockville, $\mathrm{MD}$ ) were suspended in MEM medium supplemented with $10 \%$ FCS (GIBCO, Eggenstein, Germany), plated at 6000 cell/well in 96well plates and allowed to attach for $4 \mathrm{~h}$. The medium was then aspirated and replaced with serum-free MEM containing bone matrix extracts at a dilution of 1:100 or serial dilutions of TGF- $\beta 1$ purified from human platelets (R\&D Systems, Minneapolis, MN). Plates were cultured for $21 \mathrm{~h}$ followed by pulse labeling with $1 \mu \mathrm{Ci}\left[{ }^{3} \mathrm{H}\right]$-thymidine (Amersham Buchler, Braunschweig) for $3 \mathrm{~h}$. Medium was then removed and the cells were fixed with $5 \%$ cold trichloracetic acid. Samples were solubilized in $0.25 \mathrm{~N}$ sodium hydroxide, and radioactivity was determined by liquid szintillation counting. Immediately before measurement each sample was subjected to a transient acidification at $\mathrm{pH} 2$. In accordance with findings from Jennings et al. (19), we observed no inhibition or stimulation of DNA-synthesis with applications of IGF-I, IGF-II, basic and acidic fibroblast growth factor in concentrations of up to $100 \mathrm{ng} / \mathrm{ml}$. Preincubation with two different antibodies capable of simultaneously neutralizing TGF- $\beta 1$, TGF- $\beta 2$, and TGF- $\beta 3$ (Genzyme, Cambridge, $M A$, and R\&D Systems) with each of these antibodies completely abolished the inhibitory activity of the bone extracts. The inter-assay variation was $29 \%$ with a sensitivity of $10 \mathrm{pg} / \mathrm{ml}$. Due to the high interassayvariability, four extractions were performed from each bone sample, followed by measurements of each extract in four individual bioassays.

The concentrations of the different TGF- $\beta$ species in the matrix extracts were estimated as follows: Bone matrix extract were serially diluted up to 200 -fold in minimal essential medium. Aliquots of these dilutions were then preincubated for one hour with: 1 . medium alone, 2. medium containing 1,10 , or $30 \mu \mathrm{g} / \mathrm{ml}$ of a specific antibody which either neutralized TGF- $\beta 1$, TGF- $\beta 2$, or TGF- $\beta 3$ or which simultaneously neutralized several TGF- $\beta$ species (all from R\&D Systems), 3 . medium containing $30 \mu \mathrm{g} / \mathrm{ml}$ rabbit IgG (R\&D Systems) to exclude 
nonspecific inhibition. Each of the preincubated samples was then assayed in duplicate for its inhibitory effects on DNA-synthesis in the mink lung cell assay as described above. Eight to 10 different dilutions of the matrix extracts were prepared, ranging from dilutions that had a maximal inhibitory effect on DNA-synthesis to dilutions that no longer inhibited DNA-synthesis. In addition, we performed serial dilutions of purified preparations of the particular TGF species against which the antibody was directed. The bioactivity of these dilutions had a similar range as described for the matrix extractions. As with the matrix extracts, these samples were preincubated for one hour either with medium alone, medium containing 1,10 , and $30 \mu \mathrm{g} / \mathrm{ml}$ of the TGF- $\beta$ antibody, or medium containing a similar amount of nonspecific IgG. Preliminary experiments with diluted matrix extracts had shown that the carrier solution in which the extracted bone matrix was dissolved, did not significantly interfere with the effects of TGF- $\beta$ on DNA-synthesis. The extent of inhibition of TGF- $\beta$ activity by each TGF- $\beta$ antibody was then estimated from the above dose-response-curves.

Immunoreactive bone TGF- $\beta 1$ was determined using a commercial ELISA from Genzyme (Cambridge, MA). The assay had a less than $2 \%$ cross-reactivity with TGF- $\beta 2$. Samples were assayed according to the recommendations of the manufacturer. Dilution curves of bone extracts showed good parallelism with the standard curves prepared with human TGF- $\beta 1$. Inter-assay variation was $7 \%$ with an assay sensitivity was $0.1 \mathrm{ng} / \mathrm{ml}$. Part of the samples was reevaluated with a second TGF$\beta 1$ ELISA (Promega, Madison, WI). Immunoreactive TGF- $\beta 2$ was determined using a commercial ELISA from R\&D Systems (Minneapolis, $\mathrm{MN}$ ).

\section{Normalization of the growth factor measurements}

After extraction, the residual bone matrix was resuspended twice in distilled water, lyophilized and weighed. Preliminary experiments had suggested that the dry weight of the residual bone matrix closely reflected the collagen content in the bone sample. In fact, we have found that only $3 \%$ of the total hydroxyprolin content of the bone samples was extractable (data not shown). Furthermore, the concentration of pyridinium crosslinks characteristic to mature collagen, was below the detection limit in bone matrix extracts when measured by high performance liquid chromatography (data not shown). Hydroxyproline in the bone matrix was measured after hydrolyzation in 6 molar $\mathrm{HCl}$ according to Woesner's method (20). The skeletal content of the IGFs and TGF$\beta$ in each sample was either normalized by expression per $\mathrm{mg}$ mineralized bone, per mg dry weight of the residual bone matrix, or per mg hydroxyproline content of the bone sample. The normalized values of three (IGFs) or four (TGF- $\beta$ ) separate extractions were then averaged.

\section{Statistical methods}

Statistical significance of differences was determined by analysis of variance (ANOVA) with post-hoc examination by Dunnett's test. All calculations were performed using the SAS program. Data are presented as means \pm SEM.

\section{Results}

As expected, intermittent administration of PTH via daily subcutaneous injections caused a marked time- and dose-dependent increase in the BMD of the lumbar vertebrae. The greatest BMD increase observed (39\% above control) was found in the experimental group which received daily PTH injections of 40 $\mu \mathrm{g} / \mathrm{kg}$ PTH for 12 consecutive weeks (Fig. 1). Whereas treatment with 4 and $10 \mu \mathrm{g} / \mathrm{kg}$ PTH did not significantly affect the ratio of mineralized bone weight to hydroxyprolin content in the tail vertebrae, a significant $(P=0.017$, ANOVA) $6 \%$ decline was observed with the $40 \mu \mathrm{g} / \mathrm{kg}$ dose of PTH at week 8 , suggesting a slight decrease in mineralization. Body weights and femoral lengths did not significantly differ between vehicle

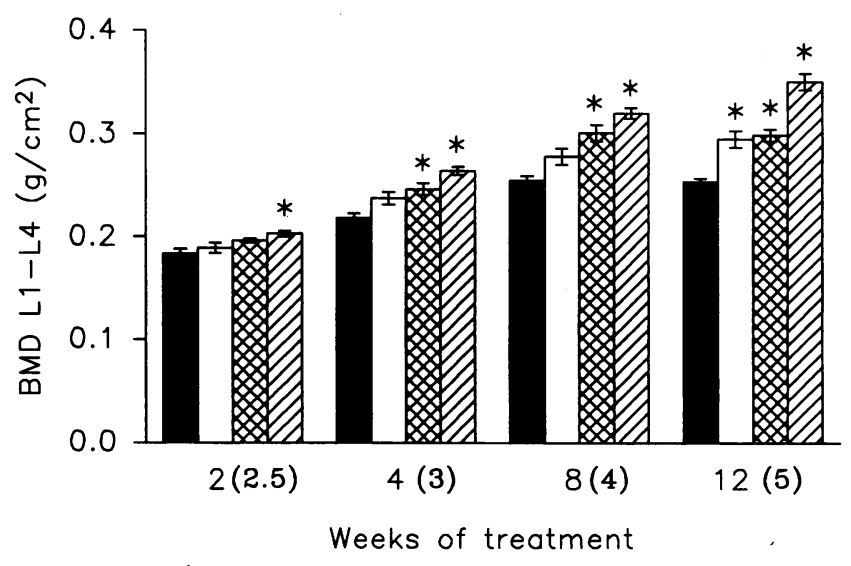

(Age at end of treatment in months)

Figure 1. Effects of PTH-treatment on bone mineral density (BMD), expressed in grams $/ \mathrm{cm}^{2}$ in the lumbar spine. Animals were given daily subcutaneous injections of either vehicle $\mathrm{a}$ or $\mathrm{hPTH}(1-34)$ in doses of $4 \square, 10 \otimes$, or $40 \square \mu \mathrm{g} / \mathrm{kg}$ body weight for $2,4,8$, or $12 \mathrm{wk}$. Data are shown as means $\pm \operatorname{SEM}(n=6)$. The age of the animals in months is shown in parentheses. * Significantly different from vehicle-treated animals, $P<0.05$.

treated and PTH treated rats throughout the course of the study (data not shown).

Fig. 2 shows the PTH-induced and age-related changes of the skeletal concentration of IGF-I, IGF-II, and TGF- $\beta$ in the proximal tail vertebrae. Intermittent treatment with PTH in doses from four up to $40 \mu \mathrm{g} / \mathrm{kg}$ PTH caused an increase in extractable IGF-I that became first significant after four weeks of PTH treatment and persisted through week 12. By week 12, skeletal IGF-I concentrations in the PTH-treated animals were on the average $30 \%$ higher than those found in the vehicletreated rats. (Fig. 2 A). Elevated tissue concentrations of IGFI after PTH-treatment were observed, regardless whether the extracted IGF-I was expressed per mg mineralized bone, $\mathrm{mg}$ of nonextractable bone matrix or mg hydroxyproline (Fig. 3, A$C$ ). Thus, this increase in skeletal IGF-I appeared to be due to an authentic increase of IGF-I sequestration into the bone matrix and not to a PTH-induced composition change of the extracellular matrix scaffold.

The PTH-mediated elevation of bone IGF-I was superimposed upon a progressive rise of skeletal IGF-I with time. By week 12, the mean IGF-I content in the vehicle-treated bone tissue was $28 \%$ higher than in the bones of the 2 wk vehicletreated rats $(P=0.004$, ANOVA) (Fig. $2 A)$.

In contrast to skeletal IGF-I, circulating IGF-I did not change after treatment with PTH, regardless of the time or dosage of PTH administered (Fig. $4 A$ ).

Intermittent treatment with PTH had no apparent effect on the skeletal concentration of IGF-II (Fig. $2 B$ ). The matrix concentrations of IGF-II in the vehicle-treated animals did not significantly change with time either. There was a remarkable $60 \%$ decline in circulating IGF-II during the course of the experiment $(P=0.0001$, ANOVA $)$, indicating that the decline in serum IGF-II that can be observed in rats within a few days after birth $(21,22)$, continues into early adulthood (Fig. $4 B$ ). PTH treatment had no effect on circulating IGF-II (Fig. $4 B$ ).

More than $80 \%$ of total TGF- $\beta$ bioactivity in bone, deter- 

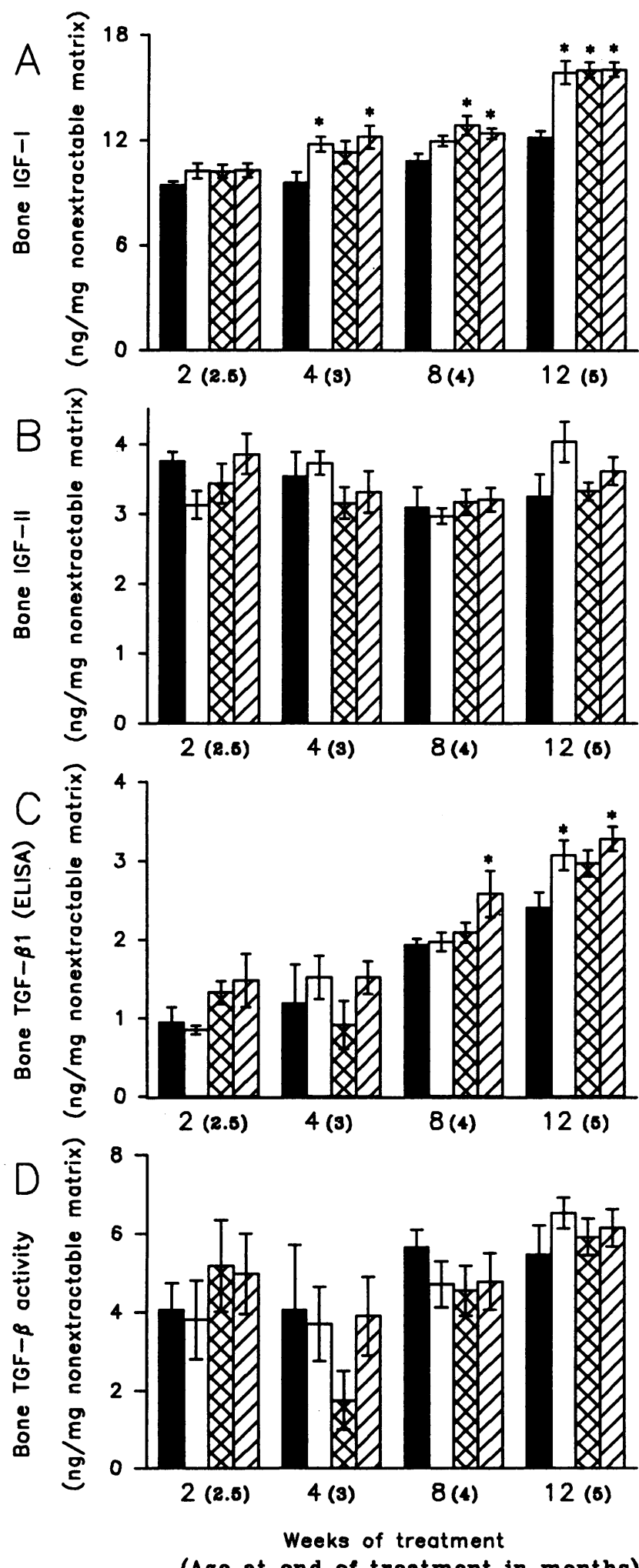

Figure 2. Effects of PTH on the bone matrix concentration of IGF-I $(A)$, IGF-II $(B)$, immunoreactive TGF- $\beta 1(C)$, and TGF- $\beta$ bioactivity determined with the mink lung cell assay $(D)$. Animals were given daily subcutaneous injections of either vehicle $\mathrm{a}$ or hPTH $(1-34)$ in doses of $4 \square, 10$, or $40 \square \mu \mathrm{g} / \mathrm{kg}$ body weight for $2,4,8$, or $12 \mathrm{wk}$ The data listed are means \pm SEM of six animals and are expressed as mined by the mink lung cell assay, could be neutralized with antibodies specific for the TGF- $\beta 1$ isoform. TGF- $\beta$ bioactivity significantly correlated with immunoreactive skeletal TGF- $\beta 1$, measured by specific ELISA $(r=0.67 ; P=0.0001)$. TGF$\beta$ bioactivity did not significantly change with age or PTH administration (Fig. $2 \mathrm{D}$ ). With ELISA measurements, no significant differences in TGF- $\beta 1$ were observed between PTHtreated and vehicle-treated rats after 2 and 4 wk of treatment; however, by week 8 , ELISA measurements showed a significantly $37 \%$ increase in TGF- $\beta 1$ in the rats receiving $40 \mu \mathrm{g} / \mathrm{kg}$ PTH as compared to the vehicle-treated animals. This difference persisted through week 12 . At the end of the 12-wk treatment period, even rats receiving the lowest dose of $4 \mu \mathrm{g} / \mathrm{kg}$ PTH had significantly elevated skeletal concentrations of immunoreactive TGF- $\beta 1$ (Fig. $2 C$ ). The stimulatory effect of PTH was accompanied by a progressive 2.5 -fold rise of TGF- $\beta 1$ between week 2 and week $12(P=0.0002$, ANOVA $)$. Both age-related and PTH-induced increases in extractable immunoreactive TGF- $\beta 1$ were confirmed by measurements using a second ELISA specific for TGF- $\beta 1$ (data not shown). Increases in immunoreactive TGF- $\beta 1$ after PTH administration were observed regardless whether the extractable TGF- $\beta 1$ was normalized to the amount of mineralized bone, nonextractable bone matrix, or hydroxyproline in the bone sample (Fig. 3, $D-F$ ).

Less than $10 \%$ of the total TGF- $\beta$ bioactivity in the mink lung cell assay was neutralized by antibodies against TGF- $\beta 2$. When measured by specific ELISA, TGF- $\beta 2$ levels at week 2 were below the detection limit for both vehicle-treated and PTHtreated rats $(<40 \mathrm{pg} / \mathrm{mg}$ nonextractable bone matrix $)$. By week 12 , concentrations of $\sim 0.05 \mathrm{ng}$ TGF- $\beta 2$ per mg nonextractable matrix had become detectable in the extracts from all groups (data not shown). However, the variability of the TGF- $\beta 2$ measurements at these low concentrations was too large for precise differences between the PTH-treated and vehicle-treated animals to be determined. Similar to TGF- $\beta 2,<10 \%$ of the total TGF- $\beta$ bioactivity in the mink lung cell assay was neutralized by antibodies against TGF- $\beta 3$. There was no significant increase in the estimated amount of TGF- $\beta 3$ activity with age or PTH treatment (data not shown).

\section{Discussion}

The mechanism for the action of PTH on bone is still incompletely understood. Data from studies in bone cell cultures have led to the hypothesis that PTH may affect the local concentration of growth factors in bone tissue, but the relevance of these findings in vivo has remained unknown. Quantitative extraction from bone matrix has previously been demonstrated to be a powerful tool for assessing hormone mediated changes of skeletal growth factors in vivo (23-25). Using this method, we show that intermittent administration of PTH raises the concentration of extractable IGF-I and TGF- $\beta 1$ in rat bone.

PTH had no significant effect on skeletal IGF-II in our study, suggesting that it may specifically increase the concentration

ng growth factor per mg nonextractable vertebral bone matrix. The age of the animals in months is shown in parentheses. * Significantly different from vehicle treated animals, $P<0.05$. 
of the IGF-I species. However, the variability of the IGF-II measurements was greater than that of the IGF-I measurements, and a small change in the concentration of IGF-II may have gone undetected.

Richardson et al. (26) have shown that when radioactive TGF- $\beta$ is applied to the periosteum of skull bone, most of the injected material remains firmly attached to the injection site for up to $16 \mathrm{~d}$ after the TGF- $\beta$ application. Only a small percentage diffused into distant sites of the bone. This supports the hypothesis that the majority of all locally produced growth factors that attach to bone matrix remains attached there and only move into deeper layers of the bone as new matrix is deposited on top of the old matrix. Since our extraction method does not discriminate between bone matrix formed before and after the onset of the PTH treatment, PTH-induced changes in the amount of extractable growth factors may not become apparent to their full extent, until the old bone matrix has been completely replaced by matrix that has been formed during the time of the PTH administration. Published dynamic histomorphometry data on 60-d-old rats suggest that a minimum of 1 or 2 mo is required for complete bone turnover of the lumbar vertebrae $(27,28)$. This may explain why significant increases in extractable growth factors in our study were observed as late as 4 and 8 wk after the onset of the PTH treatment.

We cannot completely dismiss the possibility that a small portion of endogenous IGF or TGF- $\beta$ might have escaped our extraction procedure. Nevertheless, there are several reasons supporting the belief that the extraction of the IGFs and TGF- $\beta$ in our study was quantitative. Losses due to nonspecific binding, denaturation or degradation were minimal as judged by the complete recovery of exogenously added growth factors. No additional IGF or TGF- $\beta$ release using a longer extraction period or other modifications of the extraction procedure was observed. Furthermore, even further digestion with high-grade collagenase produced no additional release of the growth factors assayed in this study. Nonwithstanding the differences in the extraction method and in the specificities of the IGF-I assays, the skeletal concentrations of IGF-I, -II and TGF- $\beta$ bioactivity per mg mineralized bone matrix reported here are in acceptable agreement with those previously reported by Finkelman et al. for rat bone matrix $(23,24)$.

Apart from the extraction procedure, the measurement of the IGFs and TGF- $\beta$ is not unproblematic. The measurement of the IGFs is particularly challenging due to the presence of high-affinity IGF-binding proteins (IGFBPs). In preliminary experiments, acidic size exclusion chromatography had only a low precision with our samples, and acid-ethanol extractions frequently fail to reliably remove these interfering binding proteins $(17,29-31)$ In our study, using highly specific antibodies for IGF-I and IGF-II, the effects of IGFBPs after acidification were suppressed by the addition of an excess of the nonmeasured peptide (IGF-I in the IGF-II assay and vice versa). This results in specific IGFBP binding and prevents the binding of the tracer to the IGFBPs present in the sample (29). Validation for our samples demonstrated that this method completely prevented any interference of the IGFBPs with the IGF measurements.

All of our measurements were performed with antibodies against human proteins, and the results are expressed as human growth factor equivalent. Since exact figures on the cross-reactivity of the rat growth factors in our assays are unknown, it is
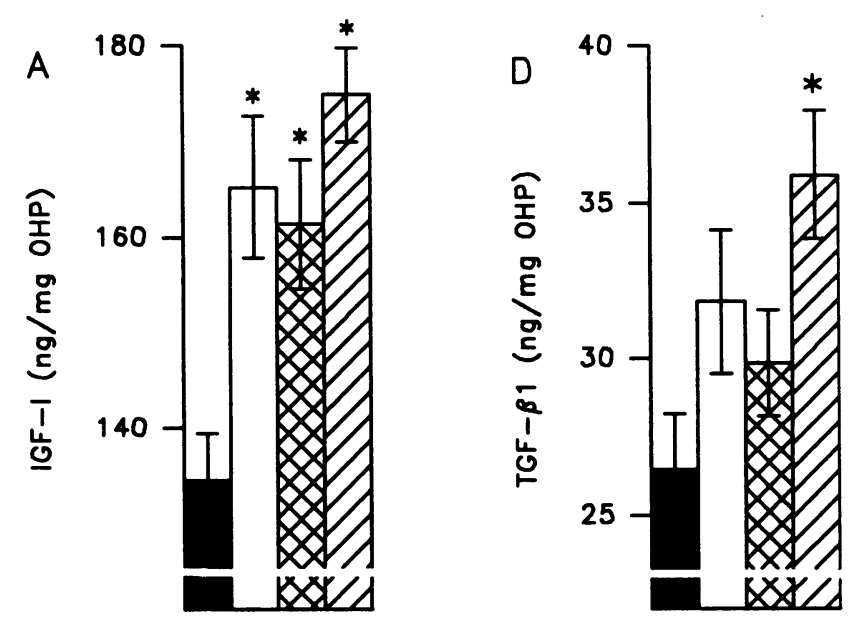

B
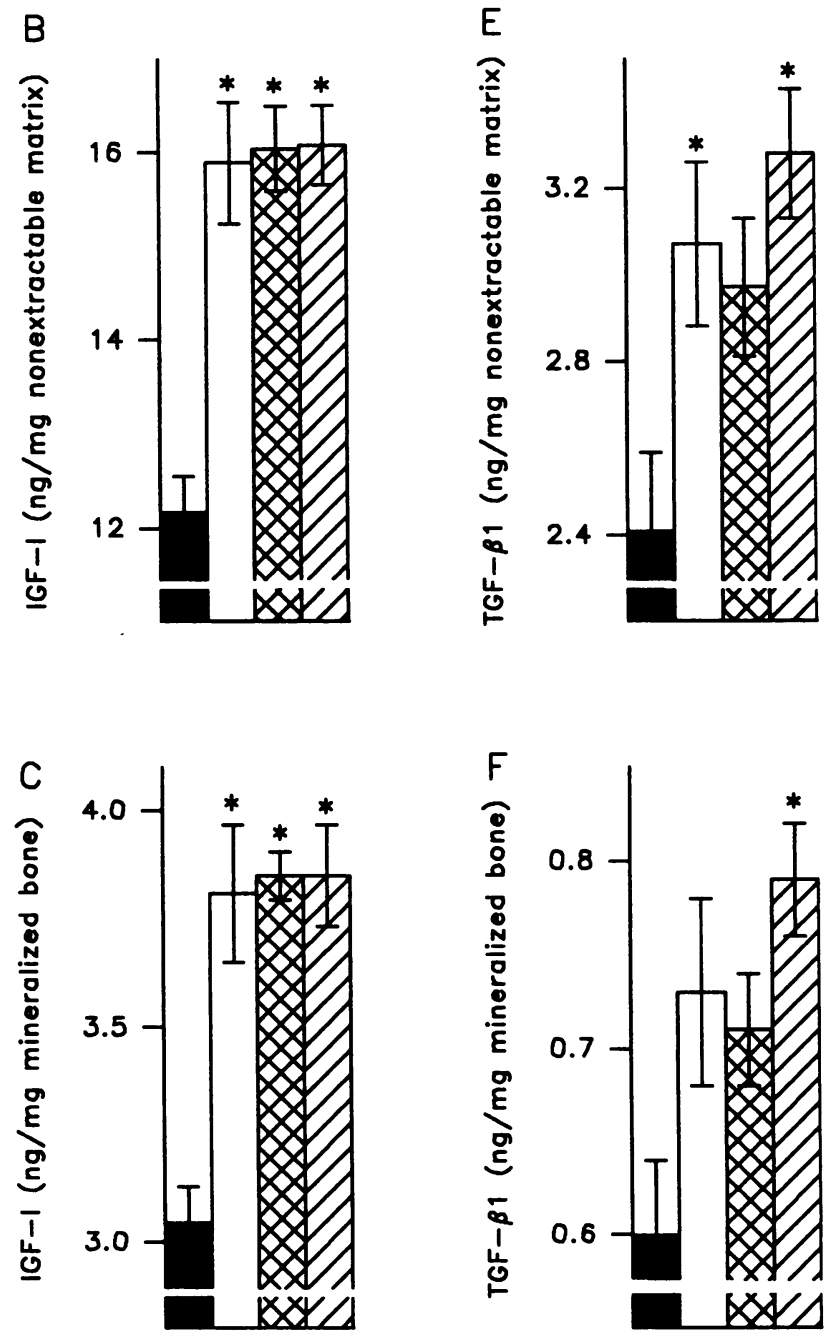

Figure 3. Animals were given daily subcutaneous injections of either vehicle $\square$ or hPTH $(1-34)$ in doses of $4 \square, 10 \otimes$, or $40 \square \mu \mathrm{g} / \mathrm{kg}$ body weight for 12 wk. Elevated skeletal concentrations of IGF-I and TGF$\beta 1$ after PTH treatment can be demonstrated irrespective of the bone matrix referent used. Data are expressed as ng growth factor per $\mathrm{mg}$ hydroxyproline (OHP) $(A, D)$, nonextractable matrix $(B, E)$, or mineralized vertebral bone $(C, F)$. Data are shown as means \pm SEM from six animals. * Significantly different from vehicle treated animals, $P<0.05$. 

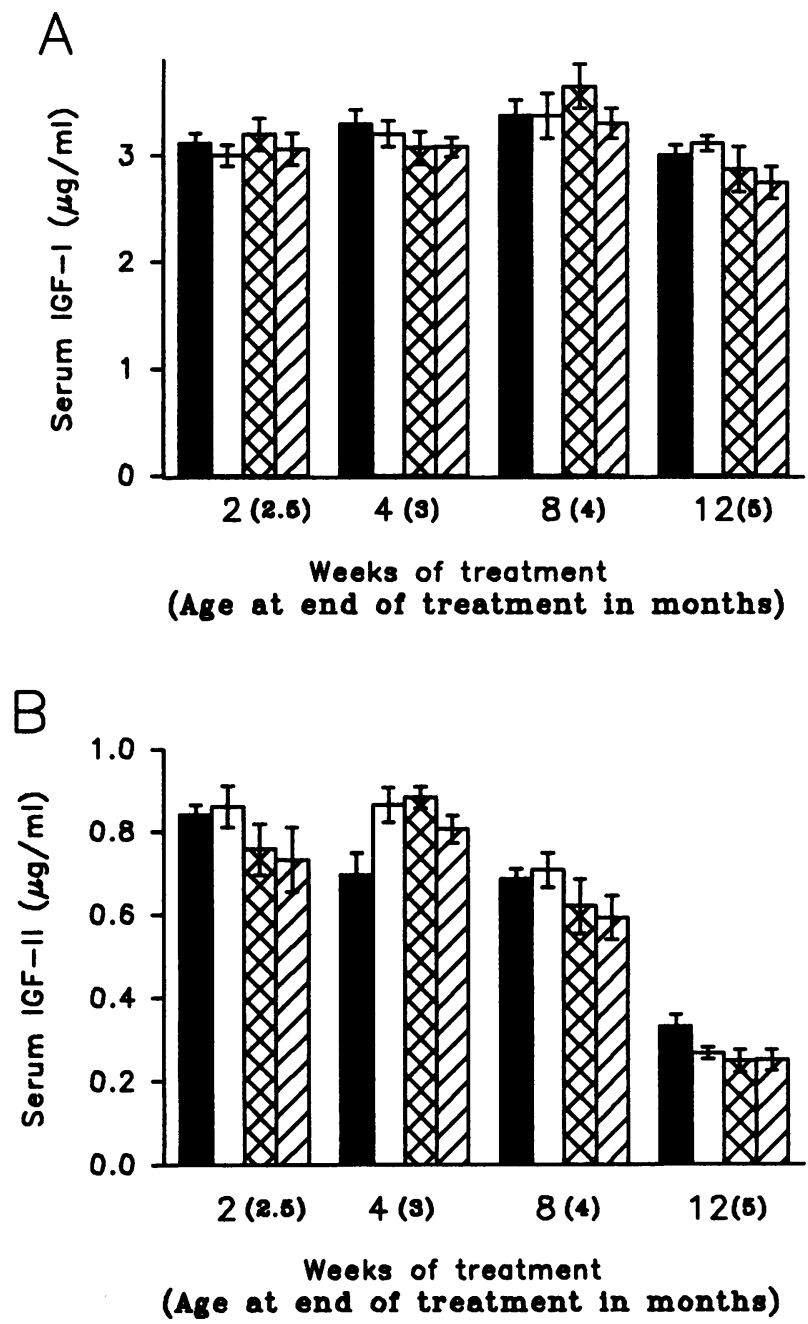

Figure 4. Intermittent treatment with PTH has no significant effects on circulating IGF-I $(A)$ and IGF-II $(B)$. Animals were given daily subcutaneous injections of either vehicle $\square$ or hPTH (1-34) in doses of $4 \square$, $10 \otimes$, or $40 \nabla \mu \mathrm{g} / \mathrm{kg}$ body weight for $2,4,8$, or 12 wk. Circulating levels of IGF-I and IGF-II were determined in blood $24 \mathrm{~h}$ after the last injection. Data are means \pm SEM from six animals. The age of the animals in months is shown in parentheses.

possible that the correct absolute concentrations of these peptides may be different from the ones reported here. However, dilution curves for human growth factors standards were parallel to those obtained with serum and bone samples from our study collective, showing that relative changes in rat IGFs and TGF$\beta$ during the PTH treatment were adequately assessed by our assays.

Until recently, TGF- $\beta$ levels have been largely determined by means of specific bioassays. One of the standard assays for TGF- $\beta$ is the mink lung cell assay, where TGF- $\beta$ activity is estimated by a inhibition of DNA-synthesis. With the development of new, specific ELISAs for different TGF- $\beta$-isoforms, we have been able to compare measurements of TGF- $\beta$ bioactivity and immunoreactive TGF- $\beta$. Although the majority of TGF- $\beta$ in our bone samples appeared to be of the TGF- $\beta 1$ isoform, we found that bioassayable TGF- $\beta$ was apparently 2 4-fold more abundant than TGF- $\beta 1$ determined by ELISA. In addition, both age-related and PTH-induced increases in immunoreactive TGF- $\beta 1$ failed to be detected with the mink lung cell assay. The exact reason for this discrepancy is not clear. However, it is conceivable that other bone matrix constituents, although being dependent on TGF- $\beta$ for affecting the growth of mink lung cells, may have modulated its effects on cell growth. Indeed, we observed that when TGF- $\beta 1$ standards were added to matrix extracts, the predicted additive inhibitory effect on DNA-synthesis was somewhat surpassed (data not shown). One of the candidates for an enhancement of TGF- $\beta$ action in bone matrix might be decorin, which has recently been shown to be a major binding protein for skeletal TGF- $\beta 1$ and to be capable of enhancing its bioactivity (32). In addition, the large interassay variability of the bioassay may have been in part responsible for the failure to detect the age-related and PTHinduced changes in TGF- $\beta$ that have been observed with the immunoassay. Whether PTH increased the amount of skeletal TGF- $\beta 2$ and TGF- $\beta 3$ remained unclear, since the concentrations of these two TGF- $\beta$ isoforms in the extracts were too low to be reliably quantified.

The results of our study are compatible with the hypothesis that PTH exerts a stimulation effect on local IGF-I and TGF$\beta 1$ production in bone cells and furtherly support previous in vitro data $(11-15)$. Nevertheless, it is also possible that other local mechanisms, such as changes in bone matrix binding proteins or tissue proteases, or indirect increases via PTH-mediated bone resorption may have contributed to the rise in extractable IGF-I and TGF- $\beta$ observed with intermittent PTH treatment. In addition, there is little doubt that serum constituents, such as $\alpha 2$-HS-glycoprotein, can be adsorbed onto the extracellular bone matrix (33). Part of the PTH-induced increases in the skeletal concentration of these factors might therefore have been due to an increased sequestration of circulating IGF-I and TGF$\beta 1$ into the bone tissue. Cosman et al. (34) reported a significant increase in IGF-I serum levels after 20 hours of PTH infusion in postmenopausal osteoporotic women being treated with PTH (1-34). In contrast, Johansson et al. (35) failed to detect any change in IGF-I concentrations in the serum of healthy persons and patients with rheumatoid arthritis after a 24-h infusion of PTH.

In the study presented here, we did not observe any increase in serum IGF-I during the course of the experiment. Based on the $95 \%$ confidence intervals of the IGF-I measurements, increases of $>10 \%$ should have been readily detected. Experience with subcutaneous growth hormone injections have shown that IGF-I levels in blood slowly rise up to $24 \mathrm{~h}$ after the injections and remain at a plateau for at least one day $(36,37)$. It is therefore unlikely that we might have missed PTH-induced increases in circulating IGF-I by our blood sampling schedule. Thus, at least for IGF-I, the present report does not provide any evidence for a systemic contribution of the PTH-induced increases in skeletal growth factors.

Both IGF-I and TGF- $\beta 1$ are potent anabolic growth factors for bone in vivo and in vitro and may thus function as local determinants of bone formation in vivo (10). Assuming that our measurements reflect the locally effective tissue concentrations of these factors at the time when the extracted bone matrix was formed, our data are consistent with the hypothesis that IGF-I and TGF- $\beta 1$ play a role in mediating the anabolic effect of PTH on bone metabolism. Finkelman et al. recently observed a decrease in TGF- $\beta$ and no change in IGF-I after ovariectomy 
in rats (24). These differential effects on the concentration of two major anabolic growth factors may be one of the reasons, why in spite of a similar increase in bone resorption, bone balance is positive with intermittent PTH treatment, but negative with estrogen withdrawal. Nevertheless, our study does not exclude that the increases in IGF-I and TGF- $\beta 1$ and in bone mass after PTH treatment may have been coincidental, and additional studies will be necessary to prove a causal relationship. It should also be noted that, in contrast to the lumbar BMD, the effects of PTH on bone IGF-I and TGF- $\beta 1$ in the tail vertebrae lacked a clear dose response, but this lack of congruency may be sufficiently explained by the considerably greater variability of the growth factor measurements as compared to that of the BMD measurements.

Due to their high bone turnover, rats are ideally suited for examining hormonal effects on the concentration of bone matrix-associated growth factors. However, one should be aware that the composition of growth factors in human bone is different from that in rat bone. In particular, bones of growing rats have more abundant IGF-I than IGF-II, whereas the opposite is true in adult human bone tissue $(23,24,38)$. It therefore remains to be established, whether the effects of PTH on growth factors in human bone are identical to those observed in our study.

Finally, it should be pointed out that, even without PTH administration, IGF-I and TGF- $\beta 1$ concentrations in bone increased with time. Age-related increases in bone matrix TGF$\beta 1$ surpassed the corresponding increases in bone mineral density of the lumbar spine. However, they paralleled the increases in bone mineral content which are representative for the total amount of bone formed during the rapid growth of the animals (data not shown). Thus, it is possible that TGF- $\beta$ may not only mediate part of the anabolic effects of PTH on bone density, but may also be essential for determining total bone mass during the natural course of bone development. It should be of considerable interest to further investigate these age-related changes and define their underlying mechanisms.

\section{Acknowledgments}

The authors acknowledge the outstanding technical assistance of Mrs. A. Braun and R. Schröter.

This work was supported by a grant from the Deutsche Forschungsgemeinschaft (Pf 190/3-1).

\section{References}

1. Tam, C. S., J. N. M. Heersche, T. M. Murray, and J. A. Parsons. 1982 Parathyroid hormone stimulates the bone apposition rate independently of its resorptive action: differential effects of intermittent and continuous administration. Endocrinology. 110:506-512.

2. Hefti, E., U. Trechsel, J. P. Bonjour, H. Fleisch, and R. Schenk. 1982 Increase of whole body calcium and skeletal mass in normal and osteoporotic adult rats treated with parathyroid hormone. Clin. Sci. 62:389-396.

3. Gunness-Hey, M., and J. M. Hock. 1984. Increased trabecular bone mass in rats treated with human synthetic parathyroid hormone. Metab. Bone. Dis. 5:177-181.

4. Slovik, D. M., D. I. Rosenthal, S. H. Doppelt, J. T. Potts Jr., M. A. Daly, J. A. Campbell, and R. M. Neer. 1986. Restoration of spinal bone in osteoporotic men by treatment with human parathyroid hormone (1-34) and 1,25-dihydroxyvitamin D. J. Bone Min. Res. 1:377-381.

5. Hock, J. M., G. J. Fonseca, and L. G. Raisz. 1988. Human parathyroid hormon- (1-34) increases bone mass in ovariectomized and orchidectomized rats. Endocrinology. 122:2899-2904.

6. Reeve, J., D. Williams, R. Hesp, P. Hulme, L. Klenerman, J. M. Zanelli,
A. J. Darby, G. W. Tregear, and J. A. Parsons. 1976. Anabolic effects of low doses of a fragment of human parathyroid hormone on the skeleton in postmenopausal osteoporosis. Lancet. 1:1035-1038.

7. Reeve, J., P. J. Meunier, J. A. Parsons, M. Bernat, O. L. M. Bijvoet, P. Courpron, C. Edouard, L. Klenerman, R. M. Neer, C. Renier, D. Slovik, F. J. Vismans, and J. T. Potts. 1980. Anabolic effect of human PTH on trabecular bone in involutional osteoporosis: a multicenter trial. Br. Med. J. 280:1340-1344.

8. Reeve, J., U. M. Davies, R. Hesp, E. McNally, and D. Katz. 1990. Treatment of osteoporosis with human parathyroid peptides and observations on effect of sodium fluoride. Br. Med. J. 301:314-318.

9. Finkelstein, J. S., A. Klibanski, E. H. Schaefer, M. D. Hornstein, I. Schiff, and R. M. Neer. 1994. Parathyroid hormone for the prevention of bone loss induced by estrogen deficiency. N. Engl. J. Med. 331:1618-1623.

10. Pfeilschifter, J., L. Bonewald, and G. R. Mundy. 1990. Role of growth factors in cartilage and bone metabolism. In Handbook of Experimental Pharmacology Vol 95/II. M. B. Sporn, and A. B. Roberts, editors. Springer, Berlin/ Heidelberg. 371-400.

11. McCarthy, T. L., M. Centrella, and E. Canalis. 1989. Parathyroid hormone enhances the transcript and polypeptide levels of insulin-like growth factor $I$ in osteoblast-enriched cultures from fetal rat bone. Endocrinology. 124:1247-1253.

12. Linkhart, T. A., and S. Mohan. 1989. Parathyroid hormone stimulates release of insulin-like growth factor-I (IGF-I) and IGF-II from neonatal mouse calvaria in organ culture. Endocrinology. 125:1484-1491.

13. Canalis, E., M. Centrella, W. Burch, and T. L. McCarthy. 1989. Insulinlike growth factor I mediates selective anabolic effects of parathyroid hormone in bone cultures. J. Clin. Invest. 83:60-65.

14. Linkhart, T. A., and M. J. Keffer. 1991. Differential regulation of insulinlike growth factor-I (IGF-I) and IGF-II release from cultured neonatal mouse calvaria by parathyroid hormone, transforming growth factor- $\beta$, and 1,25-dihydroxyvitamin $\mathrm{D}_{3}$. Endocrinology. 128:1511-1518.

15. Oursler, M. J., C. Cortese, P. Keeting, M. A. Anderson, S. K. Bonde, L. Riggs, and T. C. Spelsberg. 1991. Modulation of transforming growth factor- $\beta$ production in normal human osteoblast-like cells by $17 \beta$-estradiol and parathyroid hormone. Endocrinology. 129:3313-3320.

16. C. M. Overall. 1987. A microtechnique for dialysis of small volume solutions with quantitative recoveries. Anal. Biochem. 165:208-214.

17. Blum, W. F., M. B. Ranke, and J. R. Bierich. 1988. A specific radioimmunoassay for insulin-like growth factor II: the interference of IGF binding proteins can be blocked by excess IGF-I. Acta Endocrinol. 118:374-380.

18. Tucker, R. F., G. D. Shipley, H. L. Moses, and R. W. Holley. 1984. Growth inhibition from BSC-1 cells closely related to platelet type $\beta$ transforming growth factor. Science (Wash. DC). 226:705-707.

19. Jennings, J. C., S. Mohan, T. A. Linkhart, R. Widstrom, and D. J. Baylink. 1988. Comparison of the biological actions of TGF beta-1 and TGF beta-2: differential activity in endothelial cells. J. Cell. Physiol. 137:167-172.

20. J. E. Woessner Jr. 1961. The determination of hydroxyproline in tissue and protein samples containing small proportions of this amino-acid. Arch. Biochem. Biophys. 93:440-447.

21. Moses, A. C., S. P. Nissley, P. A. Short, M. M. Rechler, R. M. White, A. B. Knight, and O. Z. Higa. 1980. Increased levels of multiplication-stimulating activity, an insulin-like growth factor, in fetal rat serum. Proc. Natl. Acad. Sci. USA. 77:3649-3653.

22. Daughaday, W. H., K. A. Parker, S. Borowsky, B. Trivedi, and M. Kapadia. 1982. Measurement of somatomedin-related peptides in fetal, neonatal, and maternal rat serum by insulin-like growth factor (IGF) radioimmunoassay, IGFII radioreceptor assay (RRA), and multiplication-stimulating activity RRA after acid-ethanol extraction. Endocrinology. 110:575-581.

23. Finkelman, R. D., T. A. Linkhart, S. Mohan, K.-H. L. Lau, D. J. Baylink, and N. H. Bell. 1991. Vitamin D deficiency causes a selective reduction in deposition of transforming growth factor $\beta$ in rat bone: possible mechanism for impaired osteoinduction. Proc. Natl. Acad. Sci. USA. 88:3657-3660.

24. Finkelman, R. D., N. H. Bell, D. D. Strong, L. M. Demers, and D. J. Baylink. 1992. Ovariectomy selectively reduces the concentration of transforming growth factor $\beta$ in rat bone: implication for estrogen deficiency-associated bone loss. Proc. Natl. Acad. Sci. USA. 89:12190-12193.

25. Aerssens, J., R. Van Audekercke, P. Geusens, L. P. C. Schot, A. A.-H. Osman, and J. Dequeker. 1993. Mechanical properties, bone mineral content, and bone composition (collagen, osteocalcin, IGF-I) of the rat femur: influence of ovariectomy and nandrolone decanoate (anabolic steroid) treatment. Calcif. Tissue Int. 53:269-277.

26. Richardson, L., T. F. Zioncheck, E. P. Amento, L. Deguzman, W. P. Lee, $\mathrm{Y}$. Xu, and S. L. Beck. 1993. Characterization of radioiodinated recombinant human TGF- $\beta_{1}$ binding to bone matrix within rabbit skull defects. J. Bone Min Res. 8:1407-1414.

27. Li, X. J., W. S. S. Jee, H. Z. Ke, S. Mori, and T. Akamine. 1991 Age-related changes of cancellous and cortical bone histomorphometry in female sprague-dawley rats. Cells and Materials. Suppl. 1:25-35.

28. W. Sontag. 1994. Age-dependent morphometric changes in the lumbar 
vertebrae of male and female rats: comparison with the femur. Bone. 15:593601.

9. Blum, W. F., and B. H. Breier. 1994. Radioimmunoassays for IGFs and IGFBPs. Growth Regul. 4, Suppl. 1:11-19.

30. Rivero, F., L. Goya, and A. M. Pascual-Leone. 1994. Comparison of extraction methods for insulin-like growth factor-binding proteins prior to measurement of insulin-like growth factor-I in undernourished neonatal and adult rat serum. J. Endocrinol. 140:257-263.

31. Holly, J. M. P., and S. C. Cwyfan Hughes. 1994. Measuring insulin-like growth factors: why, where and how? J. Endocrinol. 140:165-169.

32. Takeuchi, Y., Y. Kodama, and T. Matsumoto. 1994. Bone matrix decorin binds transforming growth factor- $\beta$ and enhances its bioactivity. J. Biol. Chem 269:32634-32638

33. Triffitt, J. T., U. Gebauer, B. A. Ashton, M. Owen, and J. J. Reynolds. 1976. Origin of plasma $\alpha 2 \mathrm{HS}$-glycoprotein and its accumulation in bone. Nature (Lond.). 262:226-227.

34. Cosman, F., V. Shen, F. Xie, M. Seibel, A. Ratcliffe, and R. Lindsay.
1993. Estrogen protection against bone resorbing effects of parathyroid hormone infusion. Ann. Int. Med. 118:337-343.

35. Johansson, A. G., D. J. Baylink, E. af Ekenstam, E. Lindh, S. Mohan, and S. Ljunghall. 1994. Circulating levels of insulin-like growth factor-I and -II, and IGF-binding protein-3 in inflammation and after parathyroid hormone infusion. Bone Miner. 24:25-31.

36. Tapanainen, J., L. Rönnberg, H. Martikainen, M. Reinilä, R. Koistinen and M. Seppälä. 1991. Short and long term effects of growth hormone on circulating levels of insulin-like growth factor-I (IGF-I), IGF-binding protein-1, and insulin: a placebo-controlled study. J. Clin. Endocrinol. Metab. 73:71-74.

37. Laursen, T., J. O. L. Jorgensen, H. Orskov, J. Moller, A. G. Harris, and J. S. Christiansen. 1993. Effects of octreotide on insulin-like growth factor-I and metabolic indices in growth hormone-treated growth hormone-deficient patients. Acta Endocrinol. 129:399-408.

38. Dequeker, J., S. Mohan, R. D. Finkelman, J. Aerssens, and D. J. Baylink. 1993. Generalized osteoarthritis associated with increased insulin-like growth factor types I and II and transforming growth factor $\beta$ in cortical bone from the iliac crest. Arthritis \& Rheum. 36:1702-1708. 